\title{
Commentary: Individualized surgery for patients with single-ventricle physiology
}

\author{
Travis J. Wilder, MD
}

\author{
From the Department of Cardiothoracic Surgery, University of Utah, Salt Lake City, Utah. \\ Disclosures: Author has nothing to disclose with regard to commercial support. \\ Received for publication Feb 4, 2019; accepted for publication Feb 5, 2019; available ahead of print March 21 , \\ 2019. \\ Address for reprints: Travis J. Wilder, MD, Division of Cardiothoracic Surgery, University of Utah, 30 North 1900 \\ East, \#3C127 SOM, Salt Lake City, UT 84132 (E-mail: travis.wilder@hsc.utah.edu). \\ J Thorac Cardiovasc Surg 2019;158:e173-4 \\ $0022-5223 / \$ 36.00$ \\ Copyright (C) 2019 by The American Association for Thoracic Surgery \\ https://doi.org/10.1016/j.jtcvs.2019.02.022
}

Six decades of treating patients with single-ventricle physiology has taught us that the complexity and heterogeneity of the Fontan circulation does not lend itself to a "one size fits-all" strategy. Furthermore, we have learned that the technical details associated with the Fontan-Kreutzer (Fon$\tan$ ) operation can have a lasting impact on a physiologic single ventricle. The development of pulmonary arteriovenous malformations (PAVMs) is an important example of how the technical aspects of a Fontan operation-or similar total caval pulmonary connections-can influence longterm outcomes. PAVMs create an extra cardiac right-toleft shunt, which, when large enough, can impose a large physiologic burden, leading to hypoxemia and cyanosis. ${ }^{1}$ Unequal distribution of hepatic blood flow, which may result from suboptimal total caval pulmonary connection geometry, is an identified mechanism for the development of PAVMs. ${ }^{2}$

In the current issue of the Journal, Trusty and colleagues ${ }^{3}$ used Fontan surgical planning to evaluate preoperative and postoperative hemodynamics among 12 patients with single ventricles (5 Fontan revisions, 7 Fontan completions). Fontan surgical planning uses flow simulation models to predict post-Fontan hemodynamics in an effort to improve hepatic flow distribution (HFD). ${ }^{4}$ Specifically, this technique augments high-resolution axial imaging to reconstruct patient-specific anatomy. Subsequently, computational analyses are used to generate alternative surgical options to construct the "ideal" Fontan. As such, surgical planning is a powerful tool to help surgeons plan an individualized, patient-specific operation, hopefully optimizing postFontan $\mathrm{HFD}^{4}$ (Figure 1).

Previous studies have described the methodology behind preoperative surgical planning, but these are mostly small case reports. ${ }^{5}$ In addition, the use of postoperative imaging to evaluate the accuracy of surgical planning is limited to a single case series without long-term follow-up. ${ }^{6}$ The current study expands on previous knowledge by defining the accuracy of Fontan surgical planning using the largest cohort and longest follow-up to date, as well as identifying

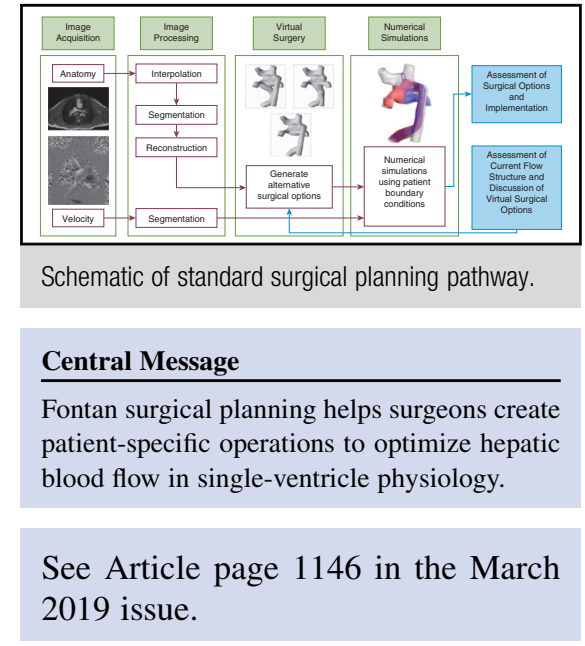

strategies for technical improvement. Trusty and colleagues ${ }^{3}$ created computational models of HFD before surgery (predicted) and after surgery (actual) to generate the predicted error in HFD. In addition, they created 2 hypothetical postoperative models assessing HFD based on "improved" anatomy or "improved" flow. The first simulation maintained the actual postoperative anatomy and used "improved" simulated flow. Conversely, the second simulation maintained actual postoperative flow and used "improved" simulated anatomy. The predicted error for the 2 hypothetical models was subsequently calculated, thus identifying if defining optimal flow or anatomy was more important in terms of creating accurate surgical planning models.

Key results showed an overall HFD prediction error of 17\% among all 12 patients irrespective of Fontan completion or revision. Preoperative comparisons with "improved" postoperative anatomy resulted in a lower HFD prediction error than for "improved" postoperative flow. The implication is that "ideal" anatomy may be the most important aspect of improving HFD. As such, models for Fontan surgical planning should focus on improved anatomy predictions to provide the best postoperative hemodynamics.

No doubt, Fontan surgical planning still requires substantial refinements before it can be practically implemented. Computational methods must continue to create improved predictions, in addition to becoming more efficient and accessible to clinicians. Furthermore, no matter how well prediction models are designed, they will never be able to account for the "unknown" that occurs during an operation. 


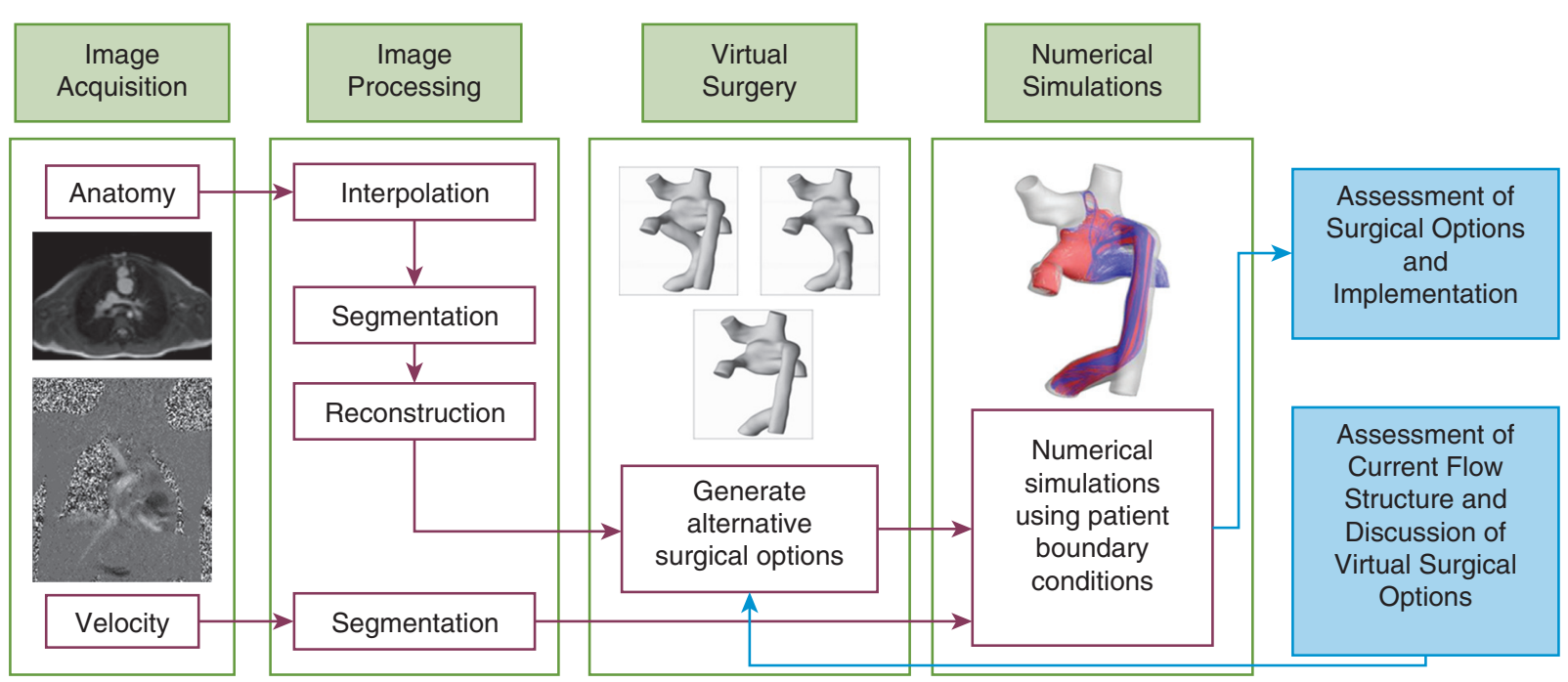

FIGURE 1. Schematic of the standard Fontan surgical planning pathway. The current study expands on the standard pathway through analysis of postoperative predicted error. $H F D$, Hepatic flow distribution. Reproduced from Fogel and colleagues. ${ }^{5}$

That said, Fontan surgical planning is an excellent example of how integrating clinical insight with technologic advancements can create individualized management strategies to improve outcomes among patients with single-ventricle physiology.

\section{References}

1. Kavarana MN, Jones JA, Stroud RE, Bradley SM, Ikonomidis JS, Mukherjee R. Pulmonary arteriovenous malformations after the superior cavopulmonary shunt: mechanisms and clinical implications. Expert Rev Cardiovasc Ther. 2014;12: 703-13.
2. de Zelicourt DA, Kurtcuoglu V. Patient-specific surgical planning, where do we stand? The example of the Fontan procedure. Ann Biomed Eng. 2016;44:174-86.

3. Trusty PM, Wei ZA, Selsnick TC, Kanter KR, Spray TL, Fogel MA, et al. The first cohort of prospective Fontan surgical planning patients with follow-up data: how accurate is surgical planning? J Thorac Cardiovasc Surg. 2019;157:1146-55.

4. Wei ZA, Trusty PM, Tree M, Haggerty CM, Tang E, Fogel M, et al. Can timeaveraged flow boundary conditions be used to meet the clinical timeline for Fontan surgical planning? J Biomech. 2017;50:172-9.

5. Fogel MA, Khiabani RH, Yoganathan A. Imaging for preintervention planning: pre- and post-Fontan procedures. Circ Cardiovasc Imaging. 2013;6:1092-101.

6. Haggerty CM, de Zélicourt DA, Restrepo M, Rossignac J, Spray TL, Kanter KR, et al. Comparing pre- and post-operative Fontan hemodynamic simulations: implications for the reliability of surgical planning. Ann Biomed Eng. 2012;40:2639-51. 